\title{
O ENSINO DE HISTÓRIA E A EDUCAÇÃO BRASILEIRA
}

\author{
Ângela Pereira Gregório ${ }^{1}$ \\ Laudijane Souza Puridade ${ }^{2}$
}

Resumo

Este arrigo aborda acerca da trajetória da educação brasileira, o surgimento da História como disciplina escolar e sua interação com as concepções historiográficas. Esta pesquisa tem como objetivo analisar a institucionalização do ensino de História no Brasil e sua relação com as propostas curriculares e o desenvolvimento do ensino crítico fundamentados na concepção de História como uma disciplina viva e elaborada a partir do presente, pautada numa perspectiva de escola voltada para a construção de uma sociedade em que os sujeitos reconheçam sua história e possam ser agentes formadores de opiniões, distanciando-se assim do modelo tradicional acrítico de ensinar História. Na metodologia foi realizada revisão bibliográfica com aporte de autores relevantes para o estudo do tema. Conclui-se que os dados obtidos apontam a necessidade de um repensar do ensino de História, que atenta as demandas da contemporaneidade, por um ensino critico, dinâmico e contextualizado.

Palavras Chave: Ensino. História. Educação Brasileira

\begin{abstract}
This article addresses the trajectory of Brazilian education, the emergence of History as a school discipline and its interaction with historiographic concepts. This research aims to analyze the institutionalization of History teaching in Brazil and its relationship with curricular proposals and the development of critical education based on the conception of History as a living discipline and elaborated from the present, based on a perspective of a school focused on the construction of a society in which the subjects recognize their history and can be opinion-forming agents, thus distancing themselves from the traditional uncritical model of teaching history. In the methodology, a bibliographic review was carried out with input from relevant authors for the study of the theme. It is concluded that the data obtained point to the need to rethink the teaching of History, which attends to the demands of contemporary times, for a critical, dynamic and contextualized teaching.
\end{abstract}

Keywords: Teaching. Story. Brazilian Education

\section{Introdução}

Ensinar História nos últimos anos no contexto da sociedade atual tem gerado muitas dúvidas. Pesquisas e teorias tentam analisar e explicar quais seriam as mudanças necessárias para atender as demandas da contemporaneidade cada vez mais conectada às novas tecnologias e transformações sociais, econômicas e políticas. Devido a isso tem-se buscando redefinir a função do ensino de História,

1 Graduada em Licenciatura em História pela Universidade Federal da Bahia- UFBA. Bacharel em História pela Universidade Federal da Bahia- UFBA. Especialista em História e Cultura Afro Brasileira pela FACCEBA. Mestranda pela Faculdade Interamericana de Ciências Sociais- FICS. Docente de História pela Secretária de Educação do Estado da Bahia. Email: angeldois28@gmail.com

${ }^{2}$ Graduada em Arquitetura e Urbanismo pela Universidade Federal da Bahia - UFBA. Graduada em Matemática pelo Centro Universitário Jorge Amado - UNIJORGE. Especialista em Matemática e Novas Tecnologias pela Universidade Católica do Salvador - UCSAL. Mestranda pela Faculdade Interamericana de Ciências Sociais - FICS. Docente de matemática pela Secretaria de Educação do Estado da Bahia. E-mail: laudmatematica@gmail.com 
não apenas nas questões relacionadas ao currículo escolar, mas também ligadas ao aprimoramento das práticas pedagógicas e da formação inicial do docente no intuito de instrumentalizá-lo para promover um ensino capaz de oportunizar a interação entre o presente e o passado na construção de um processo educativo que priorize os fundamentos históricos, da cultura e cidadania de forma crítica para os educandos.

O ensino de História não deve entender a sala de aula como um simples espaço de transmissão de informações, mas antes um ambiente de vivências, de experiências, de relações entre professor e educandos, construindo sentidos e significados. Mas para que isso ocorra muitas ações não cabem somente à figura do professor, e sim necessitam de mudanças profundas no sistema educacional brasileiro, desde a formação acadêmica do professor, até a mudança de concepção de ensino de História que se concretizou no Brasil, assim como a modernização tecnológica dos espaços escolares.

A escolha pelo tema justifica-se mediante esse contexto e da necessidade de reafirmar a relevância do ensino de História no processo formativo e da sua responsabilidade na formação crítica dos educandos. Esse momento social impõe ao ensino de História e ao professor de História um grande número de demandas, levando, assim, o educador do século XXI a repensar a sua atuação em sala de aula.

Cada momento histórico exige que a sociedade busque responder a essas perguntas, e o ensino de História baseado em concepções positivista do século XIX centrada em uma visão de História fragmentada, linear e unilateral, já não cabe mais na sociedade do século XXI, que exige um ensino de História dinâmico, crítico e contextualizado com o momento histórico, relacionado com 0 mundo contemporâneo. Vale destacar que:

O conhecimento histórico não se limita a apresentar o fato no tempo e no espaço acompanhado de uma série de documentos que comprovam sua existência. É preciso ligar o fato a temas e aos sujeitos que o produziam para buscar uma explicação. E para explicar e interpretar os fatos, é preciso uma análise, que deve obedecer a determinados princípios. Nesse procedimento, são utilizados conceitos que organizam os fatos, tornando-os inteligíveis (BITTENCOURT 2004 p.49).

O ensino de História deve ter como principal objetivo orientar o educando a desenvolver uma leitura de mundo atrelada a sua realidade social. Seu fazer 
docente não deve ater-se apenas ao currículo preestabelecido pelos órgãos reguladores da educação brasileira, mas ser uma prática que priorize 0 desenvolvimento de um ensino consciente e transformador da sociedade.

O fato não está somente em reconhecer o problema, mas em encontrar formas de superar as dificuldades enfrentadas pelos docentes no ensino de História, e que oportunize espaço para a problematização, diálogo e questionamento da realidade. Essas questões necessitam ser resolvidas e/ou minimizadas com o objetivo de oferecer aulas mais interessantes e inseridas no cotidiano dos educandos.

\section{Trajetórias da Educação no Brasil}

A compreensão das transformações ocorridas na trajetória da Educação Brasileira evidencia que a construção do ensino no país está marcada pelas dificuldades do sistema educacional em garantir acessibilidade a todos, caracterizada por um ensino excludente, baseado nos interesses de sistemas econômicos e sociais, privilegiando uma elite, alicerçada nos princípios da autoridade, limitando e muitas vezes inviabilizando a crítica e a reflexão no processo de ensino e aprendizagem.

No século XVI em 1945 com a chegada dos primeiros Jesuítas que surge a educação no Brasil, fundamentada no projeto de exploração e colonização portuguesa, baseada exclusivamente no ensino religioso (catequese). Ela constituise desde o início como um aparato do colonizador, sendo seus currículos e diretrizes definidas pelo interesse da elite colonial formada pela administração portuguesa, representantes da coroa e pelos senhores de engenho, pois "o plano legal (catequizar e instruir os índios) e o plano real se distanciaram. Os instruídos eram descendentes dos colonizadores. Os indígenas foram apenas catequizados" (RIBEIRO, 1992, p.29).

Percebe-se então claro que a obra missionaria e educativa dos Jesuítas atendiam aos interesses da política colonizadora ao definir uma divisão de ensino sendo uma para os indígenas e outra para os filhos de portugueses. A educação para os indígenas era voltada para os ensinamentos da fé cristã, totalmente acrítica e distante da realidade da vida na colônia realizadas em espações improvisados, enquanto a educação para os filhos de portugueses consistiam em ensinamentos 
mais aprofundados em diversas áreas de conhecimento em estabelecimentos organizados. $\mathrm{Na}$ intervenção da educação das elites coloniais "a organização escolar era como não poderia deixar de ser, estritamente vinculada a política colonizadora dos portugueses" (Ibid., p. 20).

A educação Jesuíta estava baseada no documento escrito por Inácio de Loiola, o Ratio Studiorum ${ }^{3}$ determinando um conjunto de normas para regulamentar o ensino nos colégios Jesuítas que tinha como finalidade orientar as atividades, metodologias e avaliações da educação nas Escolas Jesuítas. $O$ ensino e a posição do professor no modelo Jesuíta eram de submissão às autoridades, não havendo liberdade, nem reflexão dos conteúdos.

Os professores deviam obediência ao Prefeito de Estudos em tudo que se relacionava aos estudos e à disciplina das aulas, e antes de apresentar qualquer tema aos alunos era preciso expor primeiro ao prefeito para sua aprovação ou não. Pois os conteúdos de algum livro ou autor fora dos que estavam em uso não deviam ser explicados e também não podiam introduzir novos métodos no ensino (FRANCA, 1952), surgindo assim os embriões do modelo de ensino que marcaria o processo educacional do país.

Essa educação literária e humanística era, antes de tudo, a materialização do próprio espirito da Contrarreforma, que se caracterizou, sobretudo por uma enérgica reação contra o pensamento crítico, marcado também pelo apego a formas dogmáticas de pensamento, pela revalorização da Escolástica, como método e como filosofia e pela reafirmação da autoridade (ROMANELLI, 1991).

Com a expulsão dos jesuítas do Brasil em 1759 e com o advento da Reforma Pombalina ocorre uma tentativa de modificação do sistema de ensino brasileiro, com a introdução de disciplinas mais práticas e técnicas, afastadas do ensino religioso. Nesse momento surge uma educação mais estruturada, que servisse aos interesses da coroa, além disso, com essas mudanças nasce à ideia de um ensino público no Brasil.

Essas medidas tinham a intenção de organizar o ensino para servir aos interesses do Estado e não mais dá instruções religiosas (fé) como os Jesuítas. Mas

\footnotetext{
${ }^{3}$ Uma espécie de coletânea, fundamentada em experiências vivenciadas no Colégio Romano, a que foram adicionadas observações pedagógicas de diversos outros colégios, cujo objetivo era instruir rapidamente todo o jesuíta docente sobre a natureza, a extensão e as obrigações do seu cargo.
} 
esses esforços fracassaram, primeiro por que os substitutos dos Jesuítas influenciado pelos seus ensinamentos acabaram dando continuidade ao seu modelo de ensino, além disso, devido ao pouco investimento do governo foi necessário enfrentar problemas como: escassez de escolas, ausência de uma estrutura, carência de docentes e de uma sistematização educacional resultando na limitação do acesso de pessoas a educação. Vale salientar que:

\begin{abstract}
As reformas pombalinas a despeito dessas pequenas alterações desmantelou toda uma estrutura de ensino, ainda que se percebesse a manutenção dos objetivos religiosos e literários do ensino, os métodos de apego a autoridade e a disciplina estreita concretizada nas varas de marmelo e nas palmatorias, tendendo a abafar a originalidade, iniciativa e criatividade individual (ROMANELLI, 1991, s/p]).
\end{abstract}

Evidencia-se que mesmo com a derrota da Reforma Pombalina, existiram alguns avanços, como a criação do ensino público e das aulas regias ministradas por professores concursados. Com a chegada da Família Real ao Brasil em 1808, ocorreu uma mudança significativa que impulsionou investimentos na educação, resultando na criação das primeiras escolas de nível superior. Mas infelizmente essas alterações apenas favoreceriam exclusivamente a elite colonial, excluindo o acesso à educação de nível superior as camadas populares.

O foco da educação implantada pelo governo português no Brasil estava no ensino profissionalizante e na preparação para o trabalho no serviço público. Os primeiros cursos criados foram nas áreas de Medicina e Economia na Bahia e os cursos de Desenho Industrial e Práticas de Agricultura e Química no Rio de Janeiro, inicialmente somente esses dois estados foram contemplados com cursos superiores. Esses cursos eram destinados à formação da elite colonial, numa clara divisão da educação no Brasil. Diante desta realidade verifica-se a existência de uma dualidade educacional no momento que se criam modelos de ensino distintos para a elite e para as camadas populares.

No decorrer do Período Regencial o governo estabeleceu que o ensino elementar, o secundário e a formação de professores seriam de responsabilidade das províncias, e o ensino superior ficaria sob o guarda-chuva do poder central. Essa descentralização do ensino, que buscava melhorar e aumentar o número de estabelecimento de ensino, não funcionou e apenas contribuiu para o descaso dos governos com o ensino público, favorecendo o crescimento da iniciativa privada, 
perpetuando assim a dualidade existente no sistema educacional brasileiro de uma educação para elite e de outra para as camadas populares.

Durante o Período Imperial embora algumas medidas fossem determinadas não se verificou grandes avanços na educação, que ainda continuava elitista voltada para a formação dos filhos das famílias mais ricas, enquanto excluía os populares, pois a falta de investimento para a construção de escolas e formação de professores prejudicava o acesso à escola desse grupo, "a importância assumida pela educação de letrados durante toda a monarquia estava diretamente ligada a necessidade de 0 pais ter de preencher o quadro geral da administração e da política" (ROMANELLI, 1991, p.39).

No Período Republicano as mudanças ficaram restritas ao ensino superior, evidenciando novamente a dualidade do ensino brasileiro, pautada na existência de escolas para ricos e escolas para pobres, sendo o ensino superior destinado aos filhos da elite colonial. A aprovação da Constituição de 1981 consagrou a descentralização do ensino, ou melhor, a dualidade de sistemas.

Foi a partir do Movimento da Escola Nova na década de 20 liderado por educadores como Anísio Teixeira, que houve uma tentativa de mudança desse ensino dual ao se implementar uma educação inclusiva, com ensino moderno, voltado para uma educação pratica de vida, com a criação das Escolas Parques ${ }^{4}$ instaladas na Bahia e no Distrito Federal.

Mesmo com o fracasso desse movimento sua existente foi importante e representou um avanço ao questionar o modelo elitista e excludente vigente no Brasil. Ainda na década de 20, embora em caráter privado tem início uma preocupação com a educação infantil, também relacionada às mudanças desse período temos a criação da Associação Brasileira de Educação (ABE), com a função de promover debates sobre educação no Brasil, mas mesmo com esses esforços os dados do Instituto Brasileiro de Geografia e Estatística (IBGE) $)^{5}$ relacionados à década de 20 demonstram um crescimento na taxa de analfabetismo no Brasil.

A década de 30 foi marcada por importantes mudanças no sistema educacional brasileiro, como a criação do Ministério da educação, das secretarias

\footnotetext{
${ }^{4}$ Ambicioso projeto de reformulação do ensino, que previa a construção de centros populares de uma educação integral.

5 Principal provedor de informações geográficas e estatísticas do Brasil.
} 
estaduais, surgimento das escolas profissionais como o Serviço Nacional de Aprendizagem Industrial (SENAI) ${ }^{6}$ e a regulamentação do ensino industrial. Apesar dessas significativas transformações, inclusive o fato da constituição de 1934 já incluir em seu texto um capítulo inteiro sobre educação obrigatória, gratuita e laica, as desigualdades e privilégios de ensino permanecem no Brasil, foi somente na Constituição de 1942 que a educação passa a ser um direito de todos e não somente de uma minoria dominante (CUNHA, 1995).

No final da década de 40 a educação perde um pouco do seu caráter elitista com o acesso maior de pessoas as escolas secundárias e profissionalizantes, também em consonância com o contexto histórico no qual ganha repercussão as ideias do pedagogo Paulo Freire relacionadas aos métodos de alfabetização e de educação da população carente, fundamentada nas ideais de universalização, criticidade e democratização que nunca conseguiram se concretizar inteiramente na educação brasileira.

Em 1961 ocorre a promulgação da primeira Lei de Diretrizes e Bases da Educação (LDB), histórico documento que passa a regulamentar todo o sistema educacional brasileiro, instituindo disciplinas comuns a todas as áreas do conhecimento. A segunda LDB de 1971 possui mudanças presentes até hoje na educação como: obrigatoriedade de conclusão do primário de 8 anos, utilização dos termos 1 grau e 2 grau, essa objetiva conferir um caráter mais técnico a educação por ter sida fortemente influenciada pela tecnicismo defendido pela Ditadura Militar, baseada em um concepção ideológica que visava transformar pessoas em objeto de trabalho e lucro para atender as necessidades do mercado e do sistema capitalista. A educação para o trabalho era vista como:

Parte da educação geral e impactava profundamente a concepção do ensino secundário prevalecente no Brasil, desde o século XIX, e a disseminação dessa ideia entre intelectuais, educadores e políticos no final dos anos 50 e início dos anos 60 no campo educacional deve-se, em grande parte, à ideologia nacional-desenvolvimentista (SOUZA, 2008, p. 255).

O contexto neoliberal conservador apresentou transformações importantes nos anos 70, 80 e 90, provocadas pelos debates e discussões que exigiam mudanças urgentes nas propostas curriculares e na formação de professores,

${ }^{6}$ É um dos cinco maiores complexos de educação profissional do mundo e o maior da América Latina. 
resultando em mudanças como a substituição de estudos sociais por História e Geografia nos anos iniciais do Ensino Fundamental, extinção da formação de professores de História em Licenciaturas curtas, a promulgação da Lei de diretrizes e Base (LDB- 1996) e a implementação e elaboração dos PCNS (1998).

\section{O Surgimento da História e as Correntes Historiográficas}

O entendimento da institucionalização da História como disciplina escolar possibilita compreender sua relação com o ensino e as atuações docentes a partir das concepções historiográficas adotadas no cotidiano escolar. A origem da História remonta aos antigos relatos, a narrativa daqueles que testemunhavam um acontecimento nas civilizações antigas, à chamada história-testemunho.

Tradicionalmente o surgimento da História é atribuído a Civilização Grega na Antiguidade Clássica, sendo as primeiras noções de História construídas por Heródoto no século $V$ a.C e Tucídides preocupados em registrar seus feitos e transmiti-los para as gerações futuras. Nessa concepção grega o pensamento histórico tem como base uma reflexão intencionalmente voltada para a organização da memória como fundamento do sentido da sociedade, da política e da cultura respectivamente. Então para os gregos a História inicialmente tem como função preservar a memória do feito grandioso daquilo que deve se tornar imortal.

A modernidade se apropria da ideia de História grega incorporando ao seu conceito um caráter político, transformando a História em uma ferramenta para a manutenção do poder das elites nacionais, pois:

\footnotetext{
Os que detêm o poder, ou os que o exercem através do Estado, tenderão a criar representações da sociedade, nas quais os privilégios, as hierarquias, as divisões entre os que mandam e os que devem obedecer surgiram como fatos naturais (POMER, 2001, p.11).
}

As correntes historiográficas que exerceram influência sobre a História e o ensino de História podem ser agrupadas em três principais pensamentos: Positivismo, Marxismo e Escola dos Annales. Durante o século XIX a preocupação em conferir a História um caráter cientifico dominou todo pensamento histórico, sendo o surgimento da Escola Metódica ou Positivista essencial para fundamentar o status de ciência para a História. Tendência que marca com uma metodologia rigorosa e com o conhecimento do passado a História como disciplina escolar (BLOCH, 2002). 
Os defensores dessa Escola consideravam a História uma ciência linear, baseada na observação passiva do passado, cabendo ao historiador apenas o relato dos fatos e eventos, dentro dessa perspectiva o objeto falava por si mesmo, essa concepção de História estava presente no Positivismo de Augusto Comte e no Historicismo ou Historia Narrativa de Ranke que nortearam toda a construção da Historia enquanto ciência nesse período.

Segundo as teorias do Positivismo, o documento é o mais importante objeto de análise da História, pois somente se constrói História a partir de documentos que comprovem os fatos. E os métodos utilizados pelas Ciências Naturais, deveriam ser os mesmos aplicados às ciências humanas, uma vez que a História feita dessa maneira poderia realizar uma interpretação científica dos fatos, porque para os positivistas se:

\begin{abstract}
Adotassem uma atitude de distanciamento de seu objeto, sem manter relações de interdependência, obteriam um conhecimento histórico objetivo, um reflexo fiel dos fatos do passado, puro de toda distorção subjetiva. $O$ historiador para eles narra fatos realmente acontecidos e tal como eles se passaram (REIS, 2004, p.18).
\end{abstract}

A objetividade e a imparcialidade do historiador na reprodução do passado e no valor do documento oficial são os mais importantes fundamentos teóricos e contribuições de Ranke para a ciência positivista. Para o positivismo a importância dos acontecimentos históricos era realizada pelos grandes líderes nacionais, chefes de estados, reis, etc.

Dessa maneira a História se estrutura enquanto disciplina escolar como mera reprodutora do passado e de fatos notáveis, responsável pela construção de uma identidade nacional. O professor de História se torna um educador cívico, cujo principal objetivo pedagógico é levar o aluno a enxergar o passado como local da evolução linear humana, ao afirmar que:

Faz-se uma 'história comemorativa', que legitima os rituais cívicos. Nesses rituais, realizados nas datas (dia e mês) que coincidem com as do evento passado, quando os grandes heróis produzem os seus grandes feitos, procura-se a coincidência do 'atual com o eterno', em um presente intenso (lbid., p.32).

Seguindo tal concepção a História, deveria estabelecer métodos e técnicas parecidos com os das ciências Naturais, essa ideia marca todo o processo ensino 
aprendizagem em que o objetivo do ensino era a memorização e reprodução do conhecimento.

Ainda no século XIX no contexto do desenvolvimento do capitalismo e da ascensão da burguesia surge outra concepção de História que difere da Escola Metódica ou Positivista que é o Marxismo, defendendo a ideia de História enquanto um desenvolvimento evolutivo de organizações sociais subsequentes. Sendo que desta forma:

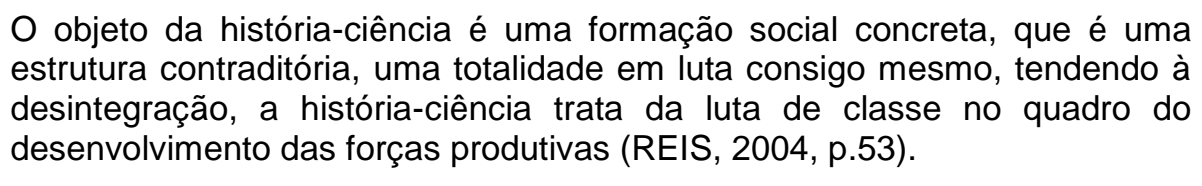

Os meios de produção formam-se nas estruturas materiais da organização social, que constituem os sistemas políticas e ideológicas de uma sociedade. As concepções marxistas criadas pelos filósofos Karl Marx e Friedrich Engels têm como foco a análise da sociedade capitalista, burguesa e liberal, dirigindo críticas a relações de trabalho e exploração do proletariado pelo sistema capitalista.

Para o Marxismo o ensino da História está fundamentado nas análises estruturalistas da dinâmica evolutiva dos modos de produção, tendo sua teoria alicerçada no materialismo histórico e na luta de classes, ao defender que:

\footnotetext{
A condição essencial da existência e da supremacia da classe burguesa é a acumulação da riqueza nas mãos dos particulares, a formação e o crescimento do capital; a condição de existência do capital é o trabalho assalariado (MARX; ENGELS, s/d. p.27).
}

$\mathrm{Na}$ perspectiva marxista a disciplina de História se tornar um instrumento revolucionário, contribuindo para a formação da identidade de classe. $\mathrm{Na}$ concepção marxista são as relações de classes e as lutas e manifestações sociais que agem como sujeitos sociais atuantes e não os grandes feitos de líderes que importam. Destaca-se que "o marxismo, enquanto ciência da história tomará como objeto as estruturas econômico-sociais, invisíveis abstratas, gerais, mas 'chão' concreto da luta de classes e das iniciativas individuais e coletivas" (op. cit., p.54).

\section{Considerações Finais}

Com o estudo da História da Educação no Brasil pode-se s observar que a educação é, portanto, um fenômeno que resulta da interação das relações dos diversos segmentos da sociedade, ao longo de sua trajetória percebe-se a sua 
importância na sociedade e na formação cultural, social e critica. A educação como intervenção inspira mudanças radicais na sociedade, na economia, nas relações humanas e na busca dos direitos, ou seja, uma sociedade sem educação não evolui

Embora a trajetória da educação no Brasil tenha apresentado mudanças significativas, ainda se percebe a perpetuação de um modelo educacional elitista e reacionário, voltado para os interesses governamentais e das classes dominantes, com pouco espaço para a criticidade, apesar de algumas exceções.

$O$ ensino de História deve ser entendido como instrumento de luta e transformação social, que permita aos educandos a construção de uma consciência crítica que supere o senso comum, para que possam dialogar com a realidade, tendo como objetivo significar aquilo que vivenciam em sala de aula de maneira reflexiva.

O ensino da História enquanto componente curricular é importante para o processo formativo, assim como para o desenvolvimento da criticidade. Pois para eles o ensino de História tem contribuído para a compreensão crítica da realidade contemporânea quando esse ensino é realizado de maneira dialogada e reflexiva, comprometido com o conhecimento histórico, relacionando os acontecimentos do passado com o presente de maneira significativa, rompendo com as tradicionais metodologias pautadas na linearidade, neutralidade e passividade dos educandos.

\section{Referências}

BITTENCOURT, C. M. F. Ensino de História: Fundamentos e Métodos. São Paulo: Cortez, 2004.

$\mathrm{BLOCH}, \mathrm{M}$. Apologia da história, ou o ofício do historiador. Rio de Janeiro: Jorge Zahar, 2002.

BRASIL. Lei de Diretrizes e Bases da Educação Nacional. Brasília: MEC,1996.

BRASIL, Secretaria de Educação Fundamental. Parâmetros Curriculares Nacionais: História. Brasília: MEC/SEF, 1998.

CUNHA, M. I. O bom professor e a sua prática. 2 ed. Campinas, SP, Papirus, 1995.

FRANCA, L. O método pedagógico dos jesuítas: o "Ratio Studiorum": Introdução e Tradução. Rio de Janeiro: Livraria Agir Editora, 1952.

POMER, L. O surgimento das nações. 10.ed. São Paulo: Editora Atual, 2001 
REIS, J C. A história entre a filosofia e a ciência. Belo Horizonte: Autêntica, 2004 RIBEIRO, M. L. S. História da Educação Brasileira: A Organização Escolar. 12. ed. São Paulo: Cortez, 1992.

ROMANELLI, O. O. História da Educação no Brasil (1930-1973). 7. ed. Petrópolis: Vozes, 1991.

SOUZA, R. F. História da organização do trabalho escolar e do currículo no século XX- Ensino primário e secundário no Brasil. São Paulo: Cortez, 2008. 